\title{
Upper Primary Students' Views Vis-à-Vis Scientific Reasoning Progress Levels in Physics
}

\author{
Tsedeke Abate ${ }^{1,2^{*}}$, Kassa Michael $^{1}$, Carl Angell ${ }^{3}$ \\ ${ }^{1}$ Department of SME, Addis Ababa University, P.O. Box 1176, Addis Ababa, ETHIOPIA \\ 2 Department of Natural Sciences, Hossana College of Teachers Education, P.O. Box 94, Hossana, ETHIOPIA \\ ${ }^{3}$ Department of Physics, University of Oslo, NORWAY
}

Received 26 November 2020 - Accepted 22 March 2021

\begin{abstract}
The purpose of this study was to explore grade eight students' views in terms of different scientific reasoning progress levels. To explore students' views, phenomenographic study was used. The qualitative analysis of students' interviews elicited three major themes of students' views about scientific reasoning progress levels: naiive, mixed, and scientific, along with the underlying ways of reasoning patterns. It was revealed that students think that scientific knowledge is static, fixed, universal, certain, and unchangeable. It is recommended that a need to consider an inquiry-based teaching in combination with the contextualized approach of nature of science in school science curriculum and classroom instruction to promote students' scientific views on the nature of science and higher scientific reasoning abilities.
\end{abstract}

Keywords: scientific reasoning, students' view, phenomenographic study, nature of science

\section{INTRODUCTION}

One of the core skills of the 21st century and goals of science education is considered to be developing students' scientific reasoning (Dole, Bloom, \& Kowalske, 2016; Fischer et al., 2014) along with proper views about scientific knowledge (Billingsley \& Fraser, 2018; Fernandes, Rodrigues, \& Ferreira, 2018). Scientific reasoning helps students to gain domain-specific knowledge, long-term academic achievement, cognitive ability, decision-making ability, and everyday problemsolving skills (Andersen \& Garcia-Mila, 2017; Bao et al., 2009; Van der Graaf, Van de Sande, Gijsel \& Segers, 2019). Some researchers argue that the societies that can survive in the midst of currently increasing and uncertain challenges are those who are equipped with disciplinary knowledge, understand science as a social enterprise, think critically and creatively, and evaluate and critique information with valid evidence (Hill, 2008; Kind \& Osborne, 2017). These days, this leads nations, educators, and researchers to focus on how scientific knowledge is constructed, how scientific reasoning skills are developed, and what is the nature of scientific knowledge (Ding, 2018; Kind \& Osborne, 2017; NRC, 2011; Osborne, Rafanelli, \& Kind, 2018).
An important aim of education globally and for subSaharan African countries in particular, is to produce citizens who can participate in ensuring sustainable development and poverty reduction (Bilican, Cakiroglu, \& Oztekin; Josh \& Verspoor, 2013). As most sub-Saharan African countries intend to attain a middle-income economy, they need a qualified workforce who is trained scientifically with the skills of the 21st century. The workforce who can retain such complex tasks sustainably is those who can understand key scientific concepts, can think critically and reasonably at higher levels, and understand modern views of the nature of science (Bilican et al., 2015).

It was reported that students develop an appropriate understanding of the nature of science and higher scientific reasoning ability when they are engaged in complex cognitive tasks such as evidence-based argumentation (Kuhn \& Dean, 2005), promoting inquisitive learning strategy (Harlen, 2013), employing higher ability learning and assessments (Opitz et al., 2017), and employing evidence-driven tools (Corcoran, Mosher \& Rogat, 2009). This suggests that when students are engaged in such complex tasks they develop higher thinking ability and view that scientific knowledge is to

(c) 2021 by the authors; licensee Modestum. This article is an open access article distributed under the terms and conditions of the Creative Commons Attribution License (http://creativecommons.org/licenses/by/4.0/).

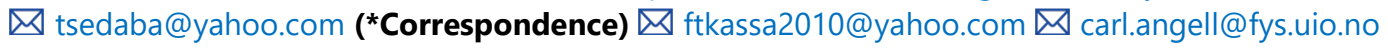




\section{Contribution to the literature}

- There is a need to explore students' views of scientific knowledge in low-income nations such as Ethiopia.

- Exploring students' view of nature of science enables one how to choose and decide what classroom instruction, teaching methods, and materials is appropriate to enhance students' learning and promote students' scientific view.

- This study explored that students demonstrated three views (naive, mixed and scientific) towards different levels of scientific reasoning progression and it was found that most students think that scientific knowledge is static, fixed, universal, certain, and unchangeable.

be constructed tentatively instead of attempting to recall and remember what is written in textbooks as it appears.

However, there is a wrong assumption among students that science is a collection of unproblematic information and facts about the world (Driver, Newton, \& Osborne, 2000; Özdemir, 2007). Most students struggle to catch the 'right answer' instead of arguing to attain the best alternatives. As it is observed in most sub-Saharan African countries classrooms, teachers evaluate students' responses based on the answer given in textbooks; once students are able to get the expected answer by guessing or any other means then the issue will be settled before having further discussions and explanations (Teshome, 2017; Verspoor, 2008). It is also well-known that the science curriculum traditionally gives emphasis to the content of scientific knowledge such as facts, theories, laws, and generalizations (Alemu, Kind, Tadesse, Atnafu, \& Michael, 2017; Bilican et al., 2015). These both hinder the development of higherlevel reasoning and renders learners to focus on lower levels learning ability like remembering and memorizing and to view scientific knowledge as mere information to be grasped. Hence, students are struggling to catch the current scientific understanding that leads to high-level reasoning (Josh \& Verspoor; 2013). There is, hence, a need to shift from an emphasis on the lower level of knowledge and the lower order cognitive abilities to the higher cognitive abilities by exploring students' pattern of reasoning and introducing proper teaching methods and assessment procedures for science education. One of the possible ways of promoting higher-order learning, such as scientific reasoning, is to engage learners in evidence-based and higher-level reasoning activities by assessing their patterns of reasoning, ways of reasoning, and their views on scientific knowledge (Kinyota, 2020; Osborne, 2013).

One of the long-standing educational problems is assessing the level of or ability to do scientific reasoning and exploring the ways students view scientific knowledge. These have been problems since science commenced as a school subject and science educators divided the science curriculum into the scientific method and science knowledge (Dunbar \& Klar, 2012; Kind \& Osborne, 2017; Lederman, 2007). Students, it was claimed, should not just learn concepts and theories scientists used to explain the world but also the method (Dunbar \& Klar, 2012). In the science curriculum, the two contrasting models, science as a body of knowledge and science as a practice dominated for centuries (Kind, 2013). These models have limitations in that they do not recognize the impact of cultural value and the contextual factors of how students think and reason (Meyer, X., \& Crawford, 2011). Since the second half of the $20^{\text {th }}$ century, however, the understanding of scientific reasoning has changed substantially, with a major impact on science education (Dunbar \& Klar, 2012; Kind, 2013). Science, it is claimed, is a social activity based on argumentation and discourse among scientists to decide what concepts and theories best fit the natural world. Scientific reasoning, accordingly, is a mix of following standardized procedures (as a process), using socially established epistemic criteria (understanding nature of science), and building on established scientific knowledge (as a product); all in a context of debate and discourse (Driver, Newton, \& Osborne, 2000; Ford, 2015; Osborne, 2013). This development makes it necessary to rethink how we teach scientific reasoning and the way how scientific knowledge is constructed in science education, and also how it is assessed. Following the change in the focus and approach towards science education, countries started to incorporate scientific reasoning and argumentation, and nature of science in their standards and devise the assessment of such skills by developing standardized tools (Akerson \& Donnelly, 2010; NRC, 2011). Consequently, there is a global shift towards students learning skills and literacy.

While scientific reasoning, along with how to develop and view scientific knowledge, is one of the skills focused globally and for sub-Saharan African countries, the effort is still in progress globally and very limited in low-income nations such as sub-Saharan African countries (Altinok et al., 2018; Bloem, 2013; Verspoor, 2008). As a result, there is a growing interest globally to assess the students' abilities of scientific reasoning in low-income nations. But the work done so far is either still limited or not addressed at all in primary schools of sub-Saharan African countries' (Creswell, Shwantner, \& Waters, 2015; Kambeyo, 2017). Most sub-Saharan African countries included skills of scientific reasoning in their curriculum, yet the students' ability of such skills 
and the way they view scientific knowledge was not explored and assessed properly (Josh \& Versoor, 2013; Kambeyo, 2017; Verspoor, 2008).

The education and training policy in Ethiopia demands focus on problem-solving and student-centred teaching to improve the quality of education and tackle the outdated teacher-centred approach by implementing various programs (Teshome, 2017; TGE 1994). However, all the efforts made so far were not considering evidencebased students' learning progression, exploring students' ways of reasoning and views towards scientific knowledge, and evidence-based tools that tell how students' conceptual understanding and reasoning develops (Abate, Michael, \& Angell, 2020). The objectives are solely meant to cover a wide range of contents, facts, solving procedural problems, demanding responses without detailed explanations and evidence (Josh \& Verspoor, 2013; Teshome, 2017) and this leads to arrive at non-evidence-based conclusions. It was revealed by Abate et al. (2020) that there is students' tendency to memorize concepts more than trying to construct a deeper conceptual understanding and engaging themselves in evidencebased activities. Abate et al. (2020) have also found that there is poor students' ability towards high-level reasoning such as evidence evaluation and drawing scientific conclusions suggesting a need for further studies to explore students' ways of reasoning and views towards scientific knowledge. This suggests that there is a need to explore students' ways of reasoning in relation to the three forms of scientific knowledge.

Scientific reasoning has been considered as a problem-solving skill and a process that involves three forms of scientific knowledge: content, procedural, and epistemic (Kind \& Osborne, 2017). It was suggested that classroom instructions and assessment development procedures need to address the three forms of scientific knowledge, learning progression and evidence-based approaches (Corcoran et al., 2009; Kennedy \& Wilson, 2007; Kind \& Osborne, 2017). Students' scientific knowledge and reasoning abilities need to progress from low to high levels based on the currently discovered scientific knowledge and understandings that consider the three forms of scientific knowledge (Ford \& Wargo, 2012; Kind, 2013; McNeill \& Krajcik, 2011; Osborne, Rafanelli, \& Kind, 2018).

Abate et al. (2020) assessed students' reasoning abilities, identifying four levels of scientific reasoning progression that included the three forms of scientific knowledge and taking into account learning progression from low level (factual knowledge) to high level scientific knowledge (drawing conclusion). The first level (factual knowledge) and second level (providing explanation) were designed in a way to assess content knowledge, level three (generating evidence) was developed to assess students' procedural knowledge and the fourth level (drawing conclusion) was to address students' epistemic knowledge. Scientific reasoning, here, was considered as a skill that involves students' providing claim and explanation, and generating valid evidence for the claim and explanation, and arriving at evidence based-conclusion. This study, therefore, aimed exploring students' views in relation to each level of the scientific reasoning progression and underlying patterns of reasoning.

Therefore, this study attempted to answer the research questions: How do Grade 8 students depict their views towards different scientific reasoning progression levels? And how do the students' views are related to the different levels of scientific reasoning progression?

\section{METHODS}

\section{Phenomenographic Approach}

Phenomenography is a research approach for examining different perspectives on reality; it refers to a method for describing the various ways in which a group of people perceives a phenomenon (Larsson \& Holmström, 2007; Marton, 1981). Some considered phenomenographic study as a strategy of inquiry in which the researcher identifies the essence of human experiences, conceptualizations, perceptions, and understanding about a phenomenon as described by participants (Creswell, 2013; Marton, 1986). The goal of phenomenography, according to Marton (1981), is to investigate the differences in people's perceptions of a given phenomenon in the surrounding environment, and the investigation is based on the variation in people's approaches to understanding the phenomenon rather than the phenomenon itself.

The goal of this study was to investigate the students' views in relation to the four levels of scientific reasoning. Phenomenographic study was used to investigate the students' patterns of reasoning and underlined views. The use of phenomenography in this research is due to the insights of the phenomenographic approach that allows one to examine the variations of views participants hold about a phenomenon, an idea, and conceptualizations of an object of study (Ayene, Kriek, \& Damtie, 2011; Marton, 1986). It is, therefore, an effective method to investigate the views of students against different levels of progression of scientific reasoning and to identify how the views of the students are linked to the different levels of scientific reasoning.

\section{Sampling}

Purposive and random samplings were used to select the participating schools and students. Six schools were selected by stratified random sampling which allowed the researchers to include schools in different locations randomly from within Hadiyya zone of the Southern Nations and Nationalities Regional State, Ethiopia. The 
reason for selecting this research site was one of the researchers visited many schools in the Hadiyya Zone when tutoring college students. From the answers of the students to the questions of their teachers, it was noted that students had problems related to scientific reasoning, and their responses represented nonscientific views. In addition to this, two of the researchers were participated in a research project Transforming Pedagogy of STEM Subjects (TPSS) that was engaged in improving the pedagogy of STEM subjects in Ethiopia (Tadesse, Kind, Alemu, Atnafu, \& Michael, 2017). Hadiyya Zone was one of the sites of the research project and it was found by the project that students have poor reasoning ability and conceptual understanding. This inspired the researchers to study the reasoning levels and related views of the students. For the interview, 12 students were selected by purposive sampling where the purpose was previous achievement that helped members from varying achievement levels which includes high, medium, and low achieving students. Marton and Booth (1997) recommended sample size between ten to twelve people for phenomenographic study. The number of students was limited to 12 because the needed data was saturated (redundancy of information was recorded) by this number.

\section{Tools and Validation}

In this study interview was used to explore students' view and underlined reasoning patterns in physics that guided the identification of students' views. To obtain information from the students, semi-structured interview was conducted. Initially, five questions were developed by the researchers. The tool was commented on by two Ph.D. candidates in physics education at Addis Ababa University and one more question was included in the final tool by the suggestion of one of the Ph.D. candidates. The candidates were selected for this task because each candidate had more than ten years of experience in teaching physics at different levels (from high school to pre-service teachers), and took assessment and scientific reasoning courses. Finally, six guiding questions were developed to identify the themes and explore the students' views and reasoning patterns in physics. The interview questions were developed to obtain information about students' views and ways of reasoning in terms of reasoning progression levels such as factual knowledge, providing an explanation, generating evidence, and drawing a conclusion. Interviews were conducted in primary schools' pedagogical centers (that are relatively free of distractions) to give students a sense of freedom and privacy, allowing them to freely answer the questions. One of the researchers conducted the interview by first requesting consent and the interview was audio recorded. Each student's interview took between 10 to 30 minutes to complete the recordings. It took just 10 minutes (shortest time) for one of the interviewees (Student 3) to complete the interview and Student 1 took about 30 minutes to complete the interview by presenting a variety of examples of physics concepts to explain his answers.

The data were also validated by the two Ph.D. candidates and six primary school physics teachers. The teachers were selected from the schools involved in this study based on the years of experience teaching physics subject at primary schools. The teachers were requested to match the findings to the students' ability of scientific reasoning and views about scientific knowledge.

\section{Data Analysis}

Phenomenography allows one to identify variation of peoples' perspectives about a construct based on their responses. In this study, Phenomenographic study enabled the researchers to identify different students' views in relation to various scientific reasoning progression levels with the help of their responses. The ways how to grade eight students depict their views and underlined reasoning patterns in physics were investigated using semi-structured interviews for the established four scientific reasoning progression levels: factual knowledge, providing an explanation, evidence generation, and drawing conclusions. Two coding cycles were used in this study. In the first cycle, in vivo coding was used to relate the students' expressions, phrases, and terms associated with their views about each level of the construct scientific reasoning (Saldana, 2013). Axial coding was used in the second cycle to identify different views related to each level of scientific reasoning. Based on the nature and characteristics of the responses, three views were identified.

\section{RESULTS}

Analysis of interview transcripts provided insights about the nature of grade eight students' scientific reasoning abilities and views. In addition to carefully listening to the audio of the interview, we thoroughly and repeatedly read the interview transcripts. Then, repeated terms, examples, expressions, and phrases that are related to the nature of scientific reasoning across various levels were coded from the transcribed text for each level of students' reasoning. In the first cycle of coding essential utterances that depict the nature and characteristics of students' reasoning abilities were identified. Then in the subsequent coding stages, these views of students' reasoning were condensed, and eventually, resulted in three major themes relevant to students' scientific reasoning experiences. The two Ph.D. candidates, from the Department of Science and Mathematics Education at Addis Ababa University, participated in auditing the interview transcripts. For the sake of validity, this study quotes verbatim taken from the students' utterances of the interview transcripts. 
Table 1. A matching matrix of themes relating views and reasoning levels

\begin{tabular}{|c|c|c|c|}
\hline \multirow{2}{*}{ Reasoning Levels } & \multicolumn{3}{|c|}{ Views } \\
\hline & Naïve & Mixed & Scientific \\
\hline \multicolumn{4}{|l|}{ Factual } \\
\hline \multicolumn{4}{|l|}{ Providing explanation } \\
\hline \multicolumn{4}{|l|}{ Seeking for evidences } \\
\hline Drawing conclusion & & & \\
\hline
\end{tabular}

Moreover, interpretations of utterances of grade eight students' scientific reasoning experiences will be provided.

As discussed above, analysis of grade eight students' interview transcripts resulted in three main themes regarding their level of scientific reasoning. These three main themes are naive, mixed, and scientific views. The interview transcripts were coded using in vivo coding during the first cycle of coding (Saldana, 2013). Then, the second cycle of coding of students' interview transcripts deployed axial coding to develop and to gather the in vivo coding results into themes. When student utterance was considered as experiential and intuitive, the utterance is coded under the theme naïve views. For example, utterances such as facts are truth, facts are absolute, $9.8 \mathrm{~m} / \mathrm{s}^{2}$ is truth value, etc. were categorized as naive views. When a student utterance was aligned or matched with the accepted scientific views, the utterance is labeled as scientific views. From students' responses, one can see that there are scientific views about the progression levels such as facts in the textbook are important to construct scientific knowledge, evidence for the presence of gravity is falling objects, etc. Such a view about scientific knowledge is termed a scientific view. When student utterance mixed intuitive and accepted scientific views, the utterance is interpreted as mixed views. Students' responses such as physics facts correctly represent a natural phenomenon, velocity represents how a fast a body moves... shown mixed students' views about physics knowledge. Mixed views amalgamate scientific views with naïve views. Often, students, who possess mixed views, combined naïve theories with scientific theories.

To sum up, naive views stand for students' reasoning based on the non-scientific, intuitive, irrelevant, and incorrect responses; mixed views refer to students' reasoning based on the students' mixed up responses of intuitive practices with scientific knowledge; scientific views refer to students' reasoning that agrees with scientific knowledge and theories.
Based on the responses of students' three themes, naïve, mixed, and scientific view, emerged in three level of reasoning namely explanation of factual knowledge, evidence-based reasoning, and drawing conclusion. Naive and scientific views were apparently emerged for the level of factual knowledge. In the next section, a detailed description of students' interview with the help of excerpts is presented and the results are presented as a matching matrix of themes relating views and reasoning levels depicted in Table 1.

\section{Factual Knowledge}

Some students viewed physics facts, theories, and laws as the laws of nature itself. They thought that once theories and laws are revealed, they will work forever. Such students views were categorized under naive view. In addition to this, students with naïve views believed that established physical theories and laws are immutable. It seems that these students took scientific knowledge as an absolute, and guided by an infallible principle of nature. This conception of students created difficulties in their attempt to generate scientific knowledge. Students with naive views took scientific knowledge as a representation of truth written on a textbook or told by their teachers. Perhaps, students, with naive views, may accept such knowledge claims based on authority. Students are not skeptical of their teachers and textbooks. Furthermore, in the naive views category, students focused on recalling facts and rote memory rather than providing explanations about physical phenomena and relations between concepts of physics. That is, students in the naive views category focused on understanding the product of science, i.e., factual knowledge not on understanding the processes of science that produced the factual knowledge. On the other hand, students, who possess scientific views, thought that the collection of various facts are the basis to build knowledge. Facts or a combination of facts is required to develop a particular understanding. Facts are the beginning of understanding physics in a new way. Hence, acquiring facts is not the goal of learning physics. Facts are conditional expressions of physical quantities and physical phenomenon. Students, with scientific views, believe that scientific facts and physics theories need to be considered as interconnected. Table 2 presents two excerpts that are taken from students interviews.

Respondent 1 in Table 2 is under the scientific view category. Students' with scientific views believed that

Table 2. Excerpts taken from students interviews about factual knowledge

Excerpts taken from students interviews
Physics deals with physical quantities which are defined and represented by simple facts. I believe the facts,
concepts, and formulae in the text books are important to understand natural phenomenon but we need to check for

its relevance. (Student 1)

I believe physics facts are absolute truth. .......for example $g=9.8 \mathrm{~m} / \mathrm{s}^{2}$ is truth value to be grasped. (Student 3)

Naïve Views 
Table 3. Excerpts taken from students' interviews about explanation of factual knowledge

Excerpts taken from students interviews
Physics, for me, is a subject which tells about the phenomenon which occurs in our surroundings. It gives
description for things we observe and practice in daily basis. For example, when we take the concept velocity I can
understand its meaning with the distance covered from starting to end point in a specific direction by measuring
time it takes to cover the path length. (Student 1)
After I learn Newton's second law of motion I understand why a moving body comes to rest. I now understand that Mixed Views
if there is no force there is no motion. Object move from one place to another because they posses force within them.
(Student 11)
One needs to give meanings for a physical phenomenon based on understanding of how the constituent elements of Naive Views
that phenomenon work. Unless one discovers and understands how things are aligned naturally, he can't give
correct relationship between them and the explanation doesn't work anymore. (Student 4)

facts are mere expressions to represent the physically occurring phenomenon. This seems a proper view of scientific facts. This view can be progressed when students develop the abilities to engage in discussions by using scientific facts to explain their claim. These students think in advance considering facts as a cornerstone for constructing and discovering up-to-date knowledge, and higher reasoning level.

The response of student 3 is an exemplar of naïve views. Students, with naïve views, believe that scientific facts are truth. According to such students' beliefs, facts are concepts, laws, and theories discovered by physicists to be grasped. Once knowledge is discovered by someone it works forever, according to some students. That is, for his students, a teacher tries to help them catch that revelation, and the responsibility of the students is trying to catch that truth. Such views seem to be an obstacle for students' high-level reasoning and knowledge constructions. In addition to this, stduentd with naive think that facts are the end product of physics knowing. Such views might hinder students from developing higher reasoning abilities. The response of Student 3 (see Table 2), as well as the responses of the other students, indicates that learning physics entails comprehending what is written in textbooks or what teachers tell them. According to this view, following the teacher's note and re-reading what is written in a textbook is sufficient. As a consequence of such perspectives, students could focus less on reasons and more on inferring meaning from their thoughts and feelings.

\section{Providing Explanation}

The interview of grade eight students indicated that five out of twelve students had a naive view about this level of reasoning. Students who had naïve views believed that the law of physics is the law of nature. They think that physics laws, theories, and principles are infallible. For such students, providing explanations is discovering naturally aligned working principles for various things in common. The excerpts of Student 4 (see Table 3), which was given below, reflected such perspectives. Based on this naïve view, the working principles of various discoveries are something that has already been existed but hidden because of lack of knowledge. This view about physics knowledge can't be expected to produce scientific reasoning. It was construed from the students' responses that students tend to make use of science concepts to establish prior belief without catching the very meaning of the concept. They were not ready to accept scientific conceptions against prior knowledge in the beginning.

Students' responses revealed that four out of twelve students believed that learning physics concepts have nothing to do with their day-to-day activities. However, after the physics concept is introduced, they tend to create meanings from what they see, touch, and do regularly. As far as the concepts are not provided in terms of concrete and tangible things, they remain meaningless expressions in their minds. Even if students at this level are willing to construct their mental theory about nature, they struggled to construct it. They struggled to relate physics concepts with day to day activities or they try to relate physics concepts with day to day experiences wrongly. Excerpts of Students 11, which showed a mixed view, is given above. The Student 11 response seemed to be a mixed view about scientific concepts with daily experiences based on a wrong understanding of physics knowledge. Such students' view and way of explanation is not expected to produce scientific reasoning because they incorrectly interpreted the law of physics in the first place.

Scientific views for explanation of factual knowledge were observed in 3/12 students' reasoning. After students having an understanding of facts to some extent, they tend to relate different physics concepts to explain a physical phenomenon. Using facts as a basic element to construct knowledge, they start to give meanings to physical quantities. This was explained by Student 1 as shown above. This indicates that the student is trying to understand the concept of velocity by relating the concepts of distance, time, and direction. The concept of velocity for him is abstract until he creates a relationship between the physical quantities distance, speed, and time with direction. This way of explaining concepts leads students to help in promoting higherlevel understanding and reasoning. 
Table 4. Excerpts taken from students interviews of evidence based reasoning

Codes
Evidence is required because we can't be sure whether a claim is correct unless we have proper evidence. Therefore,
we need to check whether a claim works or not before accepting or rejecting. Even the physics concepts, laws and
theories are man-made, theoretical and subject to change and modifications. (Student 1)
One needs evidence to understand scientific knowledge in a better way. The sources of evidences are teachers,
experienced persons and natural phenomenon. Evidences can be generated from individuals who have better
knowledge and understanding in physics. The evidence for the presence of gravity is falling objects. The evidence
for the presence of magnetic force is repulsion and attraction of magnetic materials. (Student 2)
Evidence is needed to be generated from physics laws and also from practical demonstrations. We need evidences to Naied Views
understand the law of nature. Scientists have already discovered the laws of nature but as a student I need
evidences to arrive on the knowledge discovered by scientists. The importance of generating evidence is not to
accept or reject the findings of physics but it is only to improve my understanding about physics laws and theories.
(Student 2)
It is not required to prove or disprove what has already been discovered by scientists. The concepts are already
tested and proven to be true by scientists. The findings or theories are to be accepted and learnt to use them in our
daily life. Evidences are not required to reject or accept scientific findings. Evidences are only for the sake of
understanding what has already been proved by scientists. (Student 6)

\section{Seeking Evidence}

Most students (8/12) views about evidence tend to maintain the prior beliefs or to arrive on the knowledge of the law of nature assuming the law of nature is to be manifested. (See excerpts of Student 2 provided in Table 4). For such students, physics knowledge is infallible truth already proved by scientists. They thought that the law of physics is the same as the law of nature. Based on this belief the only thing required from students is trying to catch what has already been discovered. This also indicates that the importance of evidence is only to establish and apply the knowledge which was discovered by scientists in practical aspects and to arrive at unchangeable knowledge. A sample of stduent response was provided which strengthen such view about evidence. (See excerpts of Student 6 provided in Table 4).

Students (2/12) have also shown the tendency to generate evidence for claims by relating day to day experiences with physics laws. They believed that evidence is required to construct knowledge. Any observations, experiences, demonstrations, and examples are considered valid evidence to support a claim. They are also convinced that the most accurate evidence can be generated by experienced persons, good teachers, and physical phenomenon. (See excerpts of Student 2 for particular responses). This view indicates that as far as evidence works for a particular situation it could be considered as valid. Students' seemed to be heavily dependent on external bodies and practical demonstrations to generate evidence. Students believed the significance of evidence but there is no clear view about scientific evidence. This way of viewing evidence implies that there is a challenge in identifying valid and invalid evidence.

It was found from the responses that when students are able to explain ideas, there are trends of trying to generate evidence for their claims. At the explanation level, students try to develop conceptual theories in their minds about the relationship between physics concepts and day to day activities. Students develop an interest in verifying the temporarily created mental assumptions using practical evidence. The evidence of students is characterized by trying to put things into practice. There were a few students $(2 / 12)$ who thought that evidence is required to construct new knowledge and also to accept or reject a claim. They understood that scientific knowledge is dynamic, ever-expanding, and subjected to both modifications and changes. They knew that science laws and theories are man-made and have limitations. (See excerpts of Student 1 for such explanations). Such students understood that scientific evidence is required to accept, reject, modify, and develop new knowledge. They also believed that there are valid and invalid evidence based on the relevance to support the claim.

\section{Drawing Conclusion}

Most students (9/12) believed that the law of physics is the same as the law of nature. According to such beliefs, there are no personal conclusions to be claimed scientific. Conclusions for such students are to arrive on an ever-working principle of nature for a given phenomenon. They concluded that, if someone arrives at a conclusion about a phenomenon based on valid evidence, there would be no change for such a finding. (See excerpts of Student 3 in Table 5 for such particular responses).

According to such students' beliefs, scientific conclusions are reserved for scientists and for the ones who uncovered the law of nature. The others' responsibility is only attempting to catch what has been revealed and use in life situations. One can construe from this belief that scientific conclusions are the final say about the working principle of nature. One can 
Table 5. Excerpts taken from students interviews of drawing conclusion

Excerpts taken from students interviews
We can generalize based on the available evidence, we can reject or accept based on the experimental tests but we can't Scientific
arrive on a final and ever working conclusion. The understanding of physics concepts, theories, and laws are ever
expanding and subject to modifications. (Student 1)
One can arrive at a conclusion based on the physics laws and theories. One can draw conclusion about a physical
phenomenon by relating physics knowledge. For example based on Newton's first law of motion trees out there are at
rest and will remain at rest for ever. They are always at rest unless someone moves them from where they are.
According to this law there are objects which never move for ever. (Student 5)
Scientists and philosophers draw conclusions after several trials and experiments. The laws and theories are accepted Naïve Views
as truth only when they are proved and checked the alignment with the law of nature. But one can generate available
evidences to improve his knowledge before arriving on the conclusions scientists made. (Student 3)

construe from this that scientific conclusions about the working principle of nature are final. Such students' views might be affected by the abstract nature (if not able to contextualize) of the subject. Most of the students' conclusions were also characterized by superstition, and they were not drawn based on scientific evidence. Students might need the concepts to be practically demonstrated, experimented with, and related with dayto-day activities to arrive at a valid conclusion.

Some students $(2 / 12)$ believed that conclusions are based on the experiences they observe from the environment. They attempted to draw a conclusion by mixing-up scientific theory with day-to-day activities. When students are asked to relate about a physical phenomenon based on the physics laws and theories, they give wrong generalizations. Such students claim that they draw a conclusion based on scientific knowledge but there exist contradictions with the scientific findings (See Table 5 for the excerpts of Student 5 for such particular reflections). From the response of Student 5, one can construe that the student struggled to draw a scientific conclusion. The reason for this could be the lack of correct scientific understanding of the concept of relativity. It seems that he used the law of physics to arrive at a wrong conclusion. It suggests that a lack of detailed knowledge about physics laws and theories might leads students to relate scientific knowledge with day-to-day practices to arrive at a wrong assumption, prediction, and conclusion.

A student claimed that one can arrive at currently working conclusions based on the evidence, discussions, and arguments. For such students, scientific knowledge can be modified, rejected, and accepted depending on the quality of evidence. Such students believed that no one is exempted from making mistakes; there is no absolute reality, and every finding should pass a test of time before application and taken as scientific knowledge. (See excerpts of Student 1 for such particular reflections). Even if they were a few in number some students believed that based on the valid and reliable evidence one can arrive at a tentative conclusion and they also understood that there is no ever working scientific knowledge.
Analysis of students' interview transcripts resulted in further elaborations about grade eight students' views of nature and character of scientific reasoning. In the above section, a description of students' reasoning across the four levels of reasoning was provided. In what follows, a summary of the analysis of interview questions is given (see Table 6).

To sum up, findings from the overall students' interview revealed that the level of students' scientific reasoning was dominated by factual reasoning and their views were also dominated by naïve theories. Most students mentioned their conception of facts, laws, and theories in physics. Their discourse was dominated by ideas such as Physics facts are true, universal, and certain; explanations are universal; physics ideas, concepts, laws, and theories are the source of absolute evidence; and there is true/absolute conclusion. Such responses revealed that the majority of students assumed scientific knowledge as static, fixed, universal, certain, and unchangeable. Beliefs such as scientific knowledge is unchangeable truth might push students' science learning towards recalling of physical laws and rote memorization of facts. Student interviews provide insight into the nature and characteristics of students' scientific reasoning. The next section will present overall discussion about the results of students' interview.

\section{DISCUSSIONS}

The study explored scientific reasoning ability levels and views towards different levels of scientific reasoning progression of grade eight students. In the previous section, data was analyzed qualitatively using phenomenographic approach. In this section, the result of the study is discussed vis-à-vis literature.

From this study, it was found that most high achieving students hold scientific views when compared to the low achieving ones in the previous grades. As an exemplar the student with the highest score in the previous grades (Student 1) hold scientific views towards all the four levels of scientific reasoning progression, and the lowest achiever (Student 3) reflected naive views for three levels of scientific reasoning progression. This indicates that the students' 
Table 6. Summary of students' interview

\begin{tabular}{|c|c|c|}
\hline $\begin{array}{l}\text { Reasoning } \\
\text { pattern }\end{array}$ & Sample transcripts & Descriptions \\
\hline Naive & $\begin{array}{l}\text {...9.8m } / \mathrm{s}^{2} \text { is truth value... (student } 3 \text { ) } \\
\mathrm{F}=\mathrm{ma} \text { is law of nature discovered by scientists (student } 5) \\
\text {......physics laws and theories are true evidence (student } 9 \text { ) } \\
\text {......findings are revealed truth (conclusion) (student } 11 \text { ) }\end{array}$ & $\begin{array}{l}\checkmark \text { Physics facts are truth, universal, and certain } \\
\checkmark \text { There is universal explanation } \\
\checkmark \text { Physics ideas, concepts, laws and theories are } \\
\text { the source of absolute evidence } \\
\checkmark \text { There is true/absolute conclusion (conclusion) }\end{array}$ \\
\hline Mixed & $\begin{array}{l}\text {... velocity represents how fast a body moves (student } 6 \text { ) } \\
\text { The sources of evidences are teachers, experienced } \\
\text { persons and natural phenomenon... (student } 7 \text { ) } \\
\text {....based on Newton's first law of motion trees out there } \\
\text { are at rest and will remain at rest for ever. (conclusion) } \\
\text { (student 5) }\end{array}$ & $\begin{array}{l}\checkmark \text { Mixed understanding about physics concepts } \\
\checkmark \text { Unable to differentiate between speed and } \\
\quad \text { velocity } \\
\checkmark \text { unable to identify valid and invalid evidences } \\
\checkmark \text { Unable to draw scientific conclusion }\end{array}$ \\
\hline Scientific & $\begin{array}{l}\text {...100 } \mathrm{km} \text { represents a distance... (student } 8 \text { ) } \\
\text { Velocity......is the distance covered from starting to end } \\
\text { point in a specific direction.... (student } 12 \text { ) } \\
\text {...evidence for the presence of gravity is falling objects } \\
\text { (student } 1 \text { ) } \\
\ldots . . \mathrm{F}=\text { ma can be improved (conclusion) (student } 1 \text { ) }\end{array}$ & $\begin{array}{l}\checkmark \text { Facts are foundations to construct new } \\
\text { knowledge. } \\
\checkmark \text { Provide an explanation of variable } \\
\text { relationship... } \\
\checkmark \text { Evidences can be generated from physics } \\
\text { concepts, laws and theories } \\
\checkmark \text { Understand tentative nature of conclusion }\end{array}$ \\
\hline
\end{tabular}

reasoning levels and views are affected by the prior academic achievements. That is, students with better prior knowledge and higher achievement levels are better in scientific reasoning and hold scientific views towards different levels of scientific reasoning. However, there are variations in this result among previous research findings. Some studies found that greater exposure to inquiry-based instruction, which is expected to promote students' scientific views, is associated with lower students' science achievement (OECD, 2016; Sjoberg, 2018; Zhao, 2017). Furthermore, Stadermann and Goedhart (2020) have found that students' achievement levels did not prohibit them to hold a scientific view; students with low ability levels were found to hold scientific views about physics concepts.

In the following section the result will be discussed further in terms of students' naive, mixed and scientific views with reference to the four levels of reasoning progression: factual, providing explanation, generating evidence, and drawing conclusion.

\section{Naive Views}

It was found that students viewed physics facts, concepts, laws, and theories discovered by physicists are to be recalled and remembered. They thought that once knowledge is discovered by someone it works forever. Such a view tends to be simplistic view of scientific knowledge. This is also consistent with research findings in which students think that scientific knowledge is objective and universal (Das et al., 2019; Hansson \& Leden, 2016; Lederman et al., 2013). This could be related to students' naive views about the nature of science. For such students, scientific knowledge and the law of nature are the same. Students with such views of scientific knowledge might compel to develop naive reasoning (Das et al., 2019; Lederman et al., 2013).

There was also a tendency to seek a flawless explanation. They think that providing an explanation is discovering naturally aligned working principles for various things in common instead of viewing scientific explanation as a construction of human mind with evidence. This thinking could also stem from the students' naive views of the nature of science. This is also consistent with the research finding that showed students try to construct universal scientific knowledge by assuming there is only a single method, and the way of constructing scientific knowledge is more procedural than creative (Hansson \& Leden, 2016). This indicates that they don't understand that scientific knowledge can be constructed using various ways and it is tentative in nature.

For some students, a conclusion is to arrive on an ever-working principle of nature for a specific phenomenon. They believed that, if someone comes to a conclusion about a phenomenon based on evidence, there would be no change in such findings. Such views are related to the conception of the existence of universal and constant knowledge which is the product of the unchangeable nature of physics concepts, theories, and laws (Hansson \& Leden, 2016; Niaz, 2017).

Therefore, from the result of this study along with the research findings, one can infer that students' reasoning ability and views towards scientific knowledge can be affected by authorities such as seniors' opinions and textbooks. This finding is in line with Solomon (2008) as he found that the Ethiopian culture at home and in school cultivated a child to accept the order of his supervisors without asking questions. Solomon has found that the culture expects a child to pursue the way 
his masters show; to accept his teachers taught. Though these practices currently do not seem to be commonly practiced in Ethiopia, deep-rooted religious practices and leaders, as well as beliefs in "holy" books, are common in most Ethiopian cultures (Demssie, Biemans, Wesselink, \& Mulder, 2020), and these have an impact on modern Ethiopian pedagogy (Shishigu, 2015), which may influence children's beliefs. In such a culture, seniors are considered to be always right. Such conditions could affect the way how students construct scientific knowledge and develop their thinking. This is because children enter into classroom instruction with pre-existing naive views they derive from their everyday experiences around their surroundings (Croker \& Buchanan, 2011).

According to the traditional Ethiopian culture, challenging the elders' thoughts, ideas, and ways of thinking is considered to be disrespectful to the culture, whereas shyness and silence are believed to be a sign of a good character. Students expect someone to impart knowledge rather than construct by making meaning and exercise to develop reasoning at a higher level by their efforts which is similar to a finding explored five decades ago about Ethiopian students' reasoning (Woodward, 1968). According to Woodward (1968) most Ethiopian students persist to maintain unscientific views. This is also in agreement with literature which insists that children construct mental theories to understand the world starting from early ages, but these theories need to be revised and evaluated when they grow from middle childhood to adolescence by engaging in an evidence-based dialogical discourse (Kuhn \& Dean, 2005). Different studies also indicate that students' reasoning can be affected by prior domainspecific knowledge and contextual knowledge (Andersen \& Garcia-Mila, 2017; Van der Graaf, Van de Sande, Gijsel, \& Segers, 2019). Students face difficulty in accepting scientific findings when the observations do not mach with their prior belief (Chinn \& Malhotra, 2002).

Students' naïve reasoning is also a well-established occurrence in science education. There are theoretical and empirical evidences that suggest that students come into classes with various inconsistent conceptions to scientific knowledge. Theoretically, it was confirmed that students come into class with various inconsistent conceptions about science (Croker \& Buchanan, 2011; Schauble, 1996). Some considered this naïve view as a common-sense belief about physics based on the daily experiences (Bertamini, Spooner, \& Hecht, 2004) and it is described as the way of thinking commonly shared by most people instead of thinking scientifically. Others considered this as irrelevant, incomplete, and meaningless responses (Ford \& Wargo, 2012). Some others relate students' naive reasoning as students' belief that physics is difficult to understand, abstract, and imaginary (Verspoor, 2008). Such students' view was found to be one factor that can affect students' scientific knowledge construction and higher-level reasoning (Croker \& Buchanan, 2011; Verspoor, 2008).

According to Hammer and Elby (2003), one of the most hindrances for students' scientific knowledge construction and high-level reasoning is considering students' naive conception about physics as fixed, stable, and context general. They suggested that students' naive conception about physics need to be considered as productive epistemological resources and an opportunity to help students construct new knowledge and higher-level reasoning by using effective instructions. This suggests that it is paramount to respect what students hold in their mind before formal instruction is introduced. This could create an opportunity for students to construct scientific knowledge and develop higher-level reasoning without unnecessary struggle and effort.

One of the probable reasons for the students to hold naive views and facing the difficulties of relating scientific concepts to day-to-day experiences is found to be the focus of science education that gives emphasis for the body of knowledge undermining how scientific knowledge develops (Bilican et al., 2015). Following these assumptions curriculum frameworks, curricular materials, and classroom instructions are designed in a way that compels students to learn more concepts than in-depth learning and how scientific knowledge is constructed. Even if the Ethiopian curriculum framework encourages higher-order learning and assessments, the classroom instructions and assessments are dominated by lower-order knowledge and assessment (Josh \& Verspoor, 2013; Teshome, 2017).

\section{Mixed Views}

It was also found that students attempt to construct scientific knowledge by relating with day-to-day experiences without catching scientifically accepted knowledge. They tend to make use of scientific concepts to establish prior belief without catching the very meaning of the concept. This is consistent with research findings in that students try to give meaning to physics concepts unscientifically based on the experiences they face on day-to-day experiences (Esanu \& Hatu, 2015). The reason could be that students tend to memorize facts, formulae, and problem-solving procedures, instead of trying to construct deep understanding (Elby, 1999) which stem from naïve beliefs about the nature of physics and students' persistence to maintain unscientific beliefs (Chinn \& Malhotra, 2002; Woodward, 1968), and lack of depth understanding of the concept (Harlen, 2013). They were not ready to accept scientific conceptions against prior knowledge at the very beginning of the introduction of physics concepts. Sometimes students fail to establish the scientific conceptualizations because they construct 
knowledge focusing on pursuing good grades which is also in agreement with the literature (Elby, 1999; Josh \& Verspoor, 2103). The results also indicate that students were struggling in translating what they have learned into meaningful conceptualizations. The result implies that the majority of grade eight students have a limited understanding of how scientific knowledge is constructed which is consistent with literature which reveals that most k-8 students' have faced such difficulty (Carey \& Smith, 1993). This could be one of the reasons that students faced difficulty in generating evidencebased reasoning (Corcoran et al., 2009).

As found from the students' responses one of the challenges with generating evidence was the tendency to use mixed (partially correct) evidence. Students were generating evidence from day-to-day experiences to accept or reject someone's claim. They were trying to generate evidence for explanations from examples they observe in the environment around them, but the evidence was not scientifically accepted. However, one can help students generate evidence, accept or reject a claim by providing physics concepts in a way that students can touch, feel, and demonstrate, and practice based on their environment (Erlina et al., 2018) which was found to be one of the missing elements of the schools' science.

Previous studies found that the form of instructions and assessment techniques are the primary ones that impede the development of evidence-based reasoning and the conclusion of learners. The simple way of questioning and answering techniques, without asking for more explanations, dominated by middle school science may lead to unscientific views and low-level reasoning. School assessments are exam-oriented and targeted at either passing or failing students and simply checking factual memory. Chinn and Malhota (2002) questioned overly simplistic forms of inquiry as an obstacle to promote higher reasoning abilities. Furthermore, most instructions are not designed in a way to promote higher learning abilities but incorporate a simplistic form of inquiry; assessments are also examoriented and meant to measure merely factual understanding (Anderman et al., 2012). Most classroom teaching methods concentrate on helping students pass regional exams rather than offering activities that enable students to participate in evidence-based activities (Anderman et al., 2012; Chinn \& Malhota, 2002; Josh \& Verspoor, 2013).

Studies also revealed that one of the challenges that hinder the development of students' reasoning abilities is the nature of instruction and activities provided for the students. One of the recommended remedies to overcome such problems is introducing dialogical teaching in a way that allows students to talk to each other meaningfully, provide evidence and justify their evidence along with evidence-based assessment mechanisms (Alemu, Tadesse, Michael, \& Atnafu, 2019; Tadesse et al., 2017) that has to be formative by nature.

\section{Scientific Views}

It was a hard time for most of the students to think and view that physics facts, concepts, laws, and theories are dynamic, tentative, flexible, and has elements of human imaginations and assumptions. However, it was also found that a few students think scientific knowledge as dynamic, constructed by the human mind, flexible, subjected to modifications, and change. The result suggests that there's a requirement to provide physics facts, concepts, laws, and theories that supported the day-after-day practices for the students appropriately with the support of evidence and scientific reasons to boost scientific views and a high ability level of scientific reasoning.

Research studies also revealed that students can learn physics more successfully when classroom instructions are designed based on context-sensitive resources and when students understand physics knowledge as a system of ideas to be developed progressively by reconstructing and refining current understanding instead of thinking of physics knowledge as a coherent system to be acquired from external sources such as teachers, texts and scientists (Hammer \& Elby, 2003; von Aufschnaiter \& Rogge, 2010).

\section{CONCLUSIONS}

It was found from the students' interviews that the students had demonstrated three different views, namely naïve view, mixed view, and scientific view for each of the three-level of scientific reasoning, namely providing explanation, seeking evidence, and drawing conclusion. For the level of factual knowledge only naive and scientific views were emerged. The results from the qualitative analysis of students' interviews revealed that the majority of students had shown naïve views across the four levels of reasoning. Moreover, as the complexity of the levels of scientific reasoning increases (say from factual knowledge to drawing conclusion), the naivety of students' views also increases. Most (9/12) of the students had shown naïve views for the fourth level of scientific reasoning (drawing conclusion), while four out of twelve students were naïve for the first level of scientific reasoning (factual knowledge). All in all, naïve view is the dominant view of students' understanding of the nature of science.

It was revealed from this study that many students think that scientific knowledge is static, fixed, universal, certain, and unchangeable. These students perceived physics as mere facts, concepts, laws, and theories to be grasped instead of thinking and realizing physics as a culture of practicing and exercising activities to construct tentative knowledge. It was also found that there is students' preference to memorize more concepts 
than trying to construct a meaning for the concepts. Scientific knowledge is considered by these students as an unchangeable truth to be remembered and grasped.

Author contributions: All authors have sufficiently contributed to the study, and agreed with the results and conclusions.

Funding: No funding source is reported for this study.

Declaration of interest: No conflict of interest is declared by authors.

\section{REFERENCES}

Abate, T., Michael, K., \& Angell, C. (2020). Assessment of Scientific Reasoning: Development and Validation of Scientific Reasoning Assessment Tool. EURASIA Journal of Mathematics, Science and Technology Education, 16(12), em1927. https:// doi.org/10.29333/ ejmste/9353

Akerson, V., \& Donnelly, L.A. (2010). Teaching nature of science to K-12 students: What understanding can they attain? International Journal of Science Education, 32(1), 97-124. https:// doi.org/10.1080/0950069090 2717283

Alemu, M., Kind, P. Tadesse, M., Atnafu, M., \& Michael, K. (2017). Challenges of science teacher education in low-income nations - The case of Ethiopia. ESERA-17 conference proceedings, Dublin, Ireland.

Alemu, M., Tadesse, M., Mickael, K., \& Atnafu, M. (2019). Pre-Service Physics Teachers' Physics Understanding and Upper Primary Teacher Education in Ethiopia. Bulgarian Journal of Science and Education Policy (BJSEP), 13(2), 204-224.

Altinok, N., Angrist, N., \& Patrinos, H. A. (2018). Global data set on education quality (1965-2015). World Bank. https:/ / doi.org/10.1596/1813-9450-8314

Anderman, E. M., Sinatra, G. M., \& Gray, D. L. (2012). The challenges of teaching and learning about science in the twenty-first century: Exploring the abilities and constraints of adolescent learners. StudieS in Science education, 48(1), 89-117. https:/ / doi.org/10.1080/03057267.2012.655038

Andersen, C., \& Garcia-Mila, M. (2017). Scientific reasoning during inquiry. In K. S. Taber \& B. Alpan (Eds.), Science education. new directions in mathematics and science education (pp. 105-117). Rotterdam: Sense. https://doi.org/10.1007/97894-6300-749-8_8

Ayene, M., Kriek, J., \& Damtie, B. (2011). Wave-particle duality and uncertainty principle: Phenomenographic categories of description of tertiary physics students' depictions. Physical Review Special Topics Physics Education Research, 7, 020113.

https:/ / doi.org/10.1103/PhysRevSTPER.7.020113

Bao, L., Cai, T., Koenig, K., Fang, K., Han, J., Wang, J., Liu, Q., Ding, L., Cui, L., Luo, Y., Wang, Y., Li, L., $\mathrm{Wu}, \mathrm{N}$. (2009). Learning and scientific reasoning.
Science, 323(5914), 586-587. https://doi.org/ 10.1126/science. 1167740

Bertamini, M., Spooner A., \& Hecht, H. (2004). The representation of naive knowledge about physics. In G. Malcolm (Ed.) Multidisciplinary Approaches to Visual Representations and Interpretations. Elsevier. https:/ / doi.org/10.1016/S1571-0831(04)80030-3

Bilican, K., Cakiroglu, J., \& Oztekin, C. (2015). How contextualized learning settings enhance meaningful nature of science understanding. Science Education International, 26(4), 463-487.

Billingsley, B., \& Fraser, S. (2018). Towards an understanding of epistemic insight: The nature of science in real world contexts and a multidisciplinary arena. Research in Science Education, 48(6), 1107-1113. https://doi.org/ 10.1007/s11165-018-9776-x

Bloem, S. (2013). PISA in Low- and Middle-Income Countries. OECD Education Working Papers, No. 93, OECD. Publishing. https://doi.org/10.1787/ $5 \mathrm{k} 41 \mathrm{tm} 2 \mathrm{~g} \times 2 \mathrm{vd}-\mathrm{en}$

Carey, S., \& Smith, C. (1993). On understanding the nature of scientific knowledge. Educational Psychologist, 28(3), 235-251. https://doi.org/ 10.1207 /s15326985ep2803_4

Chinn, C. A., \& Malhotra, B. A. (2002). Epistemologically authentic inquiry in schools: A theoretical framework for evaluating inquiry tasks. Science Education, 86(2), 175-218. https:/ / doi.org/10.1002/ sce.10001

Corcoran, T. B., Mosher, F. A., \& Rogat, A. D. (2009). Learning progressions in science: An evidence-based approach to reform. Consortium for Policy Research in Education. https://doi.org/10.12698/cpre.2009. rr63

Cresswell, J., Schwantner, U., \& Waters, C. (2015). A Review of International Large-Scale Assessments in Education: Assessing Component Skills and Collecting Contextual Data. PISA, The World Bank/ OECD Publishing. https:/ / doi.org/10.1787/9789264248373-en

Creswell, J. W. (2013). Qualitative inquiry and research design: Choosing among five approaches (3rd ed.). Sage.

Croker, S., \& Buchanan, H. (2011). Scientific reasoning in a real-world context: The effect of prior belief and outcome on children's hypothesis testing strategies. British Journal of Developmental Psychology, 29, 409424. https:/ / doi.org/10.1348/026151010X496906

Das, P. M., Faikhamta, C., \& Punsuvon, V. (2019). Bhutanese students' views of nature of science: A case study of culturally rich country. Research in Science Education, 49(2), 391-412. https:/ / doi.org/ $10.1007 /$ s11165-017-9611-9 
Demssie, Y. N., Biemans, H. J. A., Wesselink, R., \& Mulder, M. (2020). Combining Indigenous Knowledge and Modern Education to Foster Sustainability Competencies: Towards a Set of Learning Design Principles. Sustainability, 12(17), 6823. https:/ / doi.org/10.3390/su12176823

Ding, L. (2018). Progression trend of scientific reasoning from elementary school to university: A large-scale cross-grade survey among Chinese students. International Journal of Science and Mathematics Education, 16(8), 1479-1498. https://doi.org/ $10.1007 /$ s10763-017-9844-0

Dole, S., Bloom, L., \& Kowalske, K. (2016). Transforming pedagogy: Changing perspectives from teachercentered to learner-centered. Interdisciplinary Journal of Problem-Based Learning, 10(1), 1. https:/ / doi.org/10.7771/1541-5015.1538

Driver, R., Newton, P., \& Osborne, J. (2000). Establishing the norms of scientific argumentation in classrooms. Science Education, 84(3), 287-312. https:/ / doi.org/10.1002/(SICI)1098-237X(200005) 84:3<287::AID-SCE1>3.0.CO;2-A

Dunbar, K. N., \& Klahr, D. (2012). Scientific thinking and reasoning. In K. J. Holyoak \& R. G. Morrison (Eds.), The Oxford handbook of thinking and reasoning. Oxford Handbooks Online. https://doi.org/ 10.1093/oxfordhb/9780199734689.013.0035

Elby, A. (1999). Another reason that students learn by rote. Physics Education Research: A supplement to the American Journal of Physics, 67(7), S53-S60. https://doi.org/10.1119/1.19081

Erlina, N., Susantini, E., Wasis, W., Wicaksono, I., \& Pandiangan, P. (2018). The Effectiveness of evidence-based reasoning in inquiry-based physics teaching to increase students' scientific reasoning. Journal of Baltic Science Education, 17(6), 972-985. https:/ / doi.org/10.33225/jbse/18.17.972

Esanu, A., \& Hatu, C. (2015). The significance of prior knowledge in physics Learning. The 11th International Scientific Conference eLearning and software for Education Bucharest. Bucharest, April 2526.

Fernandes, G. W. R., Rodrigues, A. M., \& Ferreira, C. A. (2018). Conceptions of the nature of science and technology: A study with children and youths in a non-formal science and technology education setting. Research in Science Education, 48(5), 10711106. https:/ / doi.org/10.1007/s11165-016-9599-6

Fischer, F., Kollar, I., Ufer, S., Sodian, B., Hussmann, H., Pekrun, R., ... Eberle, J. (2014). Scientific reasoning and argumentation: Advancing an interdisciplinary research agenda in education. Frontline Learning Research, 2(3), 28-45. https://doi.org/10.14786/flr.v2i3.96
Ford, M. (2015). Educational Implications of Choosing "Practice" to Describe Science in the Next Generation Science Standards. Science Education, 99(6), 1041-1048. https://doi.org/10.1002/sce. 21188

Ford, M. J., \& Wargo, B. M. (2012). Dialogic framing of scientific content for conceptual and epistemic understanding. Science Education, 96, 369-391. https://doi.org/10.1002/sce.20482

Hammer, D., \& Elby, A. (2003). Tapping epistemological resources for learning physics. Journal of the Learning Sciences, 12(1), 53-90. https://doi.org/ 10.1207/S15327809JLS1201_3

Han, J. (2013). Scientific reasoning: Research, development, and assessment (Electronic Thesis or Dissertation). The Ohio State University. https: / / etd.ohiolink.edu

Hansson, L., \& Leden, L. (2016). Working with the nature of science in physics class: turning 'ordinary' classroom situations into nature of science learning situations. Physics Education, 51(5), 55001-55006. https:/ / doi.org/10.1088/0031-9120/51/5/055001

Harlen, W. (2013). Assessment and Inquiry Based Science Education: Issues in Policy and Practice. Trieste: TWAS-Strada Costiera.

Hill, C. (2008). The post-scientific society. Issues in Science and Technology on Line, 24(1), 78-84. https:/ / doi.org /10.1162/desi.2008.24.2.84

Joshi, R. D., \& Verspoor, A. (2013). Secondary Education in Ethiopia: Supporting Growth and Transformation. World Bank. https:/ / doi.org/10.1596/978-0-82139727-5

Kambeyo, L. (2017). Scientific Reasoning Skills: A Theoretical Background on Science Education. NERA Journal, 14, 40-64. http:/ / doktori.bibl.u/

Kennedy, C. A., \& Wilson, M. (2007). Using progress variables to interpret student achievement and progress. BEAR Report Series, 2006-12-01. University of California, Berkeley.

Kind, P. (2013). Establishing Assessment Scales Using a Novel Disciplinary Rationale for Scientific Reasoning. Journal of Research in Science Teaching, 50(5), 530-560. https:/ / doi.org/10.1002/tea.21086

Kind, P., \& Osborne, J. (2017). Styles of scientific reasoning: A cultural rationale for science education? Science Education, 101(1), 8-31. https:/ / doi.org/10.1002/sce.21251

Kinyota, M. (2020). The status of and challenges facing secondary science teaching in Tanzania: a focus on inquiry-based science teaching and the nature of science. International Journal of Science Education, 42(13), 2126-2144. https://doi.org/10.1080/ 09500693.2020.1813348

Kuhn, D., \& Dean, D. (2005). Is developing scientific thinking all about learning to control variables? 
Psychological Science, 16, 866-870. https:// doi.org/ 10.1111/j.1467-9280.2005.01628.x

Larsson, J., \& Holmström, I. (2007). Phenomenographic or phenomenological analysis: Does it matter: Examples from a study on anaesthesiologists' work. International Journal of Qualitative Studies on Health and Well-being, 2, 55-64. https:// doi.org/10.1177/1049732317719433

Lederman, N. G. (2007). Nature of science: past, present, and future. In S. K. Abell \& N. G. Lederman (Eds.), Handbook of Research on Science Education (pp. 831879). Lawrence Erlbaum Associates.

Lederman, N. G., Lederman, J. S., \& Antink, A. (2013). Nature of science and scientific inquiry as contexts for the learning of science and achievement of scientific literacy. International Journal of Education in Mathematics, Science and Technology, 1(33), 138147.

Marton, F. (1981). Phenomenography-describing conceptions of the world around us. Instructional Science, 10(2), 177-200. https://doi.org/10.1007/ BF00132516

Marton, F. (1986). Phenomenography: A research approach to investigating different understandings of reality. Journal of Thought, 21(3), 28-49.

Marton, F., \& Booth, S. (1997). Learning and Awareness. Lawrence Erlbaum.

McNeill, K. L., \& Krajcik, J. S. (2011). Supporting Grade 5-8 students in constructing explanations in science: The claim, evidence, and reasoning framework for talk and writing. Pearson.

Meyer, X., \& Crawford, B. A. (2011). Teaching science as a cultural way of knowing: Merging authentic inquiry, nature of science, and multicultural strategies. Cultural Studies of Science Education, 6(3), 525-547. https://doi.org/10.1007/s11422-0119318-6

National Research Council. (2011). A Framework for K12 Science Education: Practices, Crosscutting Concepts, and Core Ideas. Committee on a Conceptual Framework for New K-12 Science Education Standards. Board on Science Education, Division of Behavioral and Social Sciences and Education. The National Academies Press.

Niaz, M. (2017). Evolving nature of objectivity in the history of science and its implications for science education (Vol. 46). Springer. https://doi.org/10.1007/978-3-31967726-2

OECD. (2016). PISA 2015 Results (Volume I): Excellence and Equity in Education. OECD Publishing. https://doi.org/10.1787/9789264266490-en

Opitz, A., Heene, M., \& Fischer, F. (2017). Measuring scientific reasoning-a review of test instruments. Educational Research and Evaluation, 23(3-4), 78-101. https:/ / psycnet.apa.org/doi/10.1080/13803611.20 17.1338586

Osborne, J. (2013). The 21st century challenge for science education: Assessing scientific reasoning. Thinking Skills and Creativity, 10, 265-279. https://doi.org/ 10.1016/j.tsc.2013.07.006

Osborne, J., Rafanelli, S., \& Kind, P. (2018). Toward a more coherent model for science education than the crosscutting concepts of the next generation science standards: The affordances of styles of reasoning. Journal of Research in Science Teaching, 55(7), 962-981. https:/ / doi.org/10.1002/tea.21460

Özdemir, G. (2007). The effects of the nature of science beliefs on science teaching and learning. Uludağ Üniversitesi Eğitim Fakültesi Dergisi, 20(2), 355-372. http:/ / hdl.handle.net/11452/11377

Saldana, J. (2013). The coding manual for qualitative researchers (2nd ed.). Sage.

Schauble, L. (1996). The development of scientific reasoning in knowledge-rich contexts. Developmental Psychology, 32(1), 102-119. https:// doi.org/10.1037/0012-1649.32.1.102

Shishigu, A. (2015). Foundation of Curriculum in Ethiopia: Historical, Philosophical, Psychological and Sociological Perspectives [Paper presentation]. 33rd May Annual International Educational Conference of Bahir Dar University, Ethiopia, May 8-9, 2015.

Sjøberg, S. (2018). The power and paradoxes of PISA: Should we sacrifice Inquiry-Based Science Education (IBSE) to climb on the Rankings? NorDiNa, Nordic studies in science education, 14(2), 186-202. https:// doi.org/10.5617/nordina.6185

Smith, J. A. (2007). Hermeneutics, human sciences and health: Linking theory and practice. International Journal of Qualitative Studies on Health and Well-being, 2, 3-11. https:// doi.org/10.1080/1748262060101 6120

Solomon, A. (2008). Policy Formulation, Curriculum Development, and Implementation in Ethiopia. The Book Center, AAU.

Stadermann, H. K. E., \& Goedhart, M. J. (2020). Secondary school students' views of nature of science in quantum physics. International Journal of Science Education, 42(6), 1-20. https://doi.org/ 10.1080/09500693.2020.1745926

Tadesse, M., Kind, P., Alemu, M., Atnafu, M., \& Michael, K. (2017). Improving Scientific Reasoning Through Dialogical Teaching - An Intervention in Ethiopian Teacher Education [Paper presentation]. ESERA Conference, Dublin City University, Dublin, Ireland, 21-25 April 2017.

Teshome, N. B. (2017). Classroom Participation and Development of Student Attitudes: A Study of Active Learning Practices in Ethiopian Primary Education. International Journal of Humanities Social 
Sciences and Education (IJHSSE), 4(3), 67-68. https:/ / doi.org/10.20431/2349-0381.0403008

Transitional Government of Ethiopia [TGE]. (1994). Education and Training Policy. EMPDA.

Van der Graaf, J., Van de Sande, E., Gijsel, M., \& Segers, E., (2019). A combined approach to strengthen children's scientific thinking: direct instruction on scientific reasoning and training of teacher's verbal support, International Journal of Science Education, 41(9), 1119-1138. https://doi.org/10.1080/ 09500693.2019 .1594442

Verspoor, A. M. (2008). At the crossroads: choices for secondary education in Sub-Saharan Africa. World
Bank Publications, The World Bank, number 6537, Juni. https:/ / doi.org/10.1596/978-0-8213-7113-8

von Aufschnaiter, C., \& Rogge, C. (2010). Misconceptions or Missing Conceptions? Eurasia Journal of Mathematics, Science and Technology Education, 6(1), 3-18. https://doi.org/10.12973/ ejmste/ 75223

Woodward, D. H. (1969). Teaching Science in Ethiopia. American Scientist, 57(4), 338A-344A. https:/ / www. jstor.org/stable/27828735

Zhao, Y. (2017). What works may hurt: Side effects in education. Journal of Educational Change, 18, 1-19. https://doi.org/10.1007/s10833-016-9294-4

\section{http://www.ejmste.com}

